
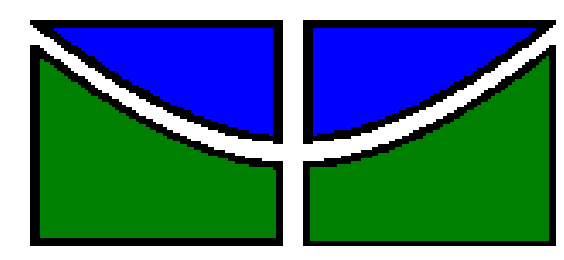

UNIVERSIDADE DE BRASÍLIA

Faculdade de Educação - UAB/UnB/ MEC/SECAD Curso de Especialização em Educação na Diversidade e Cidadania, com Ênfase em EJA

\author{
ANA MARIA DE ALBUQUERQUE SANTOS \\ GENIVAL SANTOS DE MORAES \\ GILDO BEZERRA DOS SANTOS
}

DIFERENÇAS INDIVIDUAIS NA SALA DE AULA DE EJA

BRASÍLIA, DF

Julho/2010 
UNIVERSIDADE DE BRASÍLIA

Faculdade de Educação - UAB/UnB/ MEC/SECAD

Curso de Especialização em Educação na Diversidade e Cidadania, com Ênfase em EJA

\section{DIFERENÇAS INDIVIDUAIS NA SALA DE AULA DE EJA}

ANA MARIA DE ALBUQUERQUE SANTOS

GENIVAL SANTOS DE MORAES

GILDO BEZERRA DOS SANTOS

PROJETO DE INTERVENÇÃO LOCAL

BRASÍLIA, DF Julho/2010 
UNIVERSIDADE DE BRASÍLIA

Faculdade de Educação - UAB/UnB/ MEC/SECAD

Curso de Especialização em Educação na Diversidade e

Cidadania, com Ênfase em EJA

ANA MARIA DE ALBUQUERQUE SANTOS

GENIVAL SANTOS DE MORAES

GILDO BEZERRA DOS SANTOS

\section{DIFERENÇAS INDIVIDUAIS NA SALA DE AULA DE EJA}

Trabalho de conclusão do Curso de Especialização em Educação na Diversidade e Cidadania, com Ênfase em EJA, como parte dos requisitos necessários para obtenção do grau de Especialista na Educação de Jovens e Adultos

PROFESSOR ORIENTADOR (ERLANDO DA SILVA RÊSES) 
Dedicamos o presente conteúdo a nossa família, que nos ajudou e auxiliou em todos os momentos, aos amigos que nos incentivaram e a todos que nunca desistem de seus sonhos. 


\section{AGRADECIMENTOS}

Agradecemos primeiramente a Deus por ter nos dar força para chegarmos até aqui.

À professora Alzira Aparecida Diogo pelos esclarecimentos prestados durante o curso.

Aos demais professores e orientadores da casa pelos conhecimentos transmitidos. 
Por aprendizagem significativa, entendo aquilo que provoca profunda modificação no indivíduo. Ela é penetrante, e não se limita a um aumento de conhecimento, mas abrange todas as parcelas de sua existência.

(Carl Rogers) 


\section{RESUMO}

O projeto, Diferenças Individuais na Sala de Aula de EJA, se constitui da necessidade de atender de forma diferenciada aos níveis de aprendizagem em que se encontram os alunos no início do semestre, visando equalizá-los de forma sistemática, proporcionando um atendimento não somente homogêneo, mas individualizado em todo o percurso da série em que o mesmo se encontra. Na sala de aula observa-se e constata-se a existência de diversos tipos de alunos, com diferenças individuais sejam elas como dificuldade de aprendizagem, grandes diferenças de idades, alunos adolescentes e jovens que deixaram de ser crianças, porém, ainda não são adultos, alunos diferentes por serem portadores de necessidades especiais, portanto, diferentes nos modos de pensar e agir estudando na mesma sala. Esse aluno adulto busca a escola tardiamente para alfabetizar-se, ou mesmo cursar algumas séries do ensino na Educação de Jovens e Adultos. Nessa perspectiva, proporcionar aos alunos um atendimento que o envolva de forma mais efetiva durante as aulas é de fundamental necessidade, buscando uma melhoria considerável tanto na aprendizagem quanto na inserção do mesmo na sociedade como um todo. O objetivo é atender os alunos de forma individualizada de acordo com os níveis de aprendizagem diagnosticados no início do semestre letivo. O projeto se desenvolverá de acordo com alguns passos. Sua aplicação deverá ocorrer sempre no inicio do semestre e se estender ao longo do mesmo. Tem como parceiros apenas a comunidade escolar. Sua avaliação será feita de forma contínua.

Palavras-chave: Diferenças, Dificuldade, Aprendizagem, Aluno 


\section{SUMÁRIO}

1. IDENTIFICAÇÃO

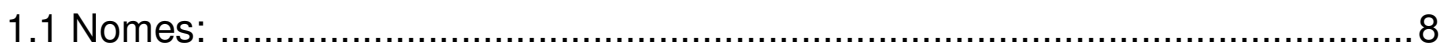

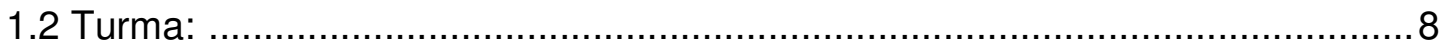

1.3 Endereço de Correspondência................................................................

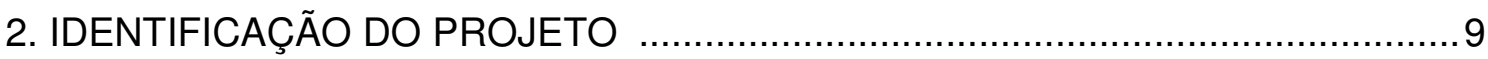

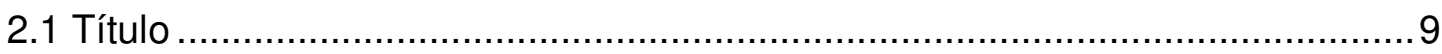

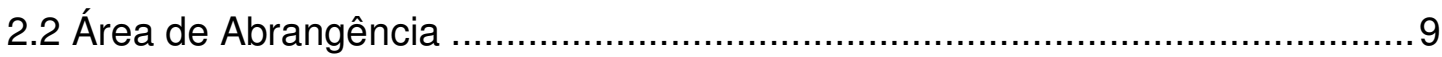

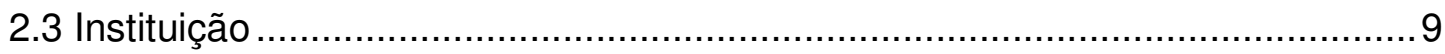

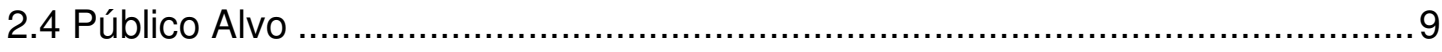

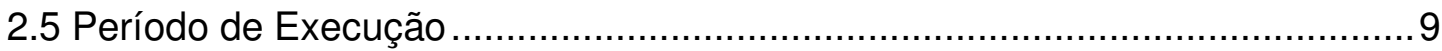

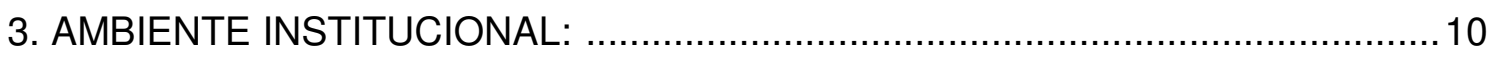

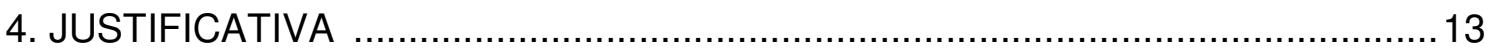

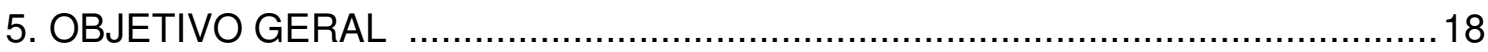

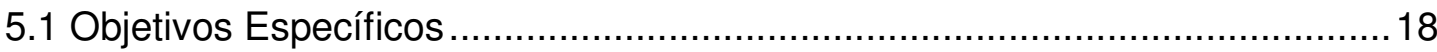

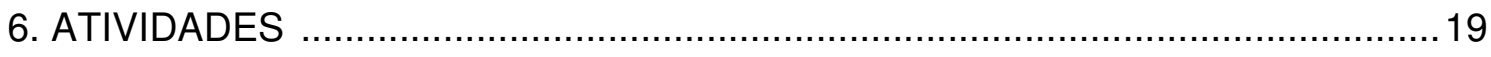

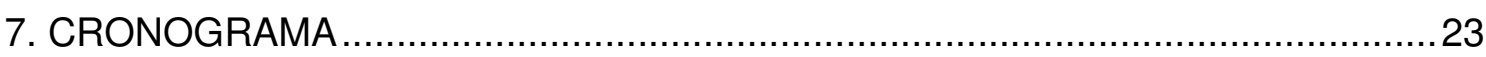

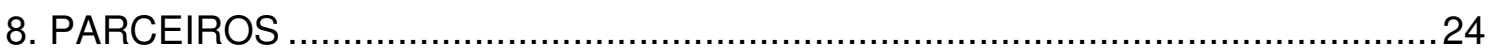

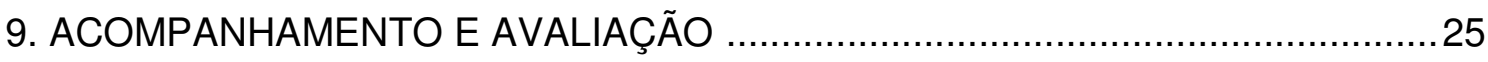

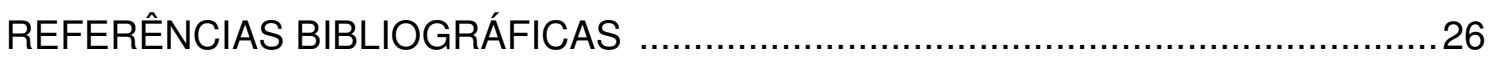




\section{IDENTIFICAÇÃO}

\subsection{NOMES:}

Ana Maria De Albuquerque Santos

Genival Santos De Moraes

Gildo Bezerra Dos Santos

\subsection{TURMA: I}

\subsection{ENDEREÇO DE CORRESPONDÊNCIA:}

Ana Maria de Albuquerque Santos

SQS 415 Bloco R Apto 103 - Asa Sul - Brasília DF - CEP 70298-180

Fone: (61) 8481-9203

E-mail: amasann@ig.com.br

Genival Santos de Moraes

Rua 09 Quadra 15 Casa 05 Morada Nobre, Valparaíso - GO - CEP 72870-333

E-mail: geninhomensagens@yahoo.com.br

Fone: (61) 85080076

Gildo Bezerra dos Santos

Quadra 537 Casa 07 Parque Estrela D'Alva VI, Novo Gama-GO - CEP 72860500

E-mail: gildobezerra@yahoo.com.br

Fone: (61) 81460382 


\section{IDENTIFICAÇÃO DO PROJETO}

2.1 TíTULO: Diferenças Individuais na Sala de Aula de EJA

2.2 ÁREA DE ABRANGÊNCIA: Santa Maria.

2.3. INSTITUIÇÃO: Centro de Ensino Fundamental 201 de Santa Maria, CL (Conjunto Logístico) 201 de Santa Maria DF, tel: (61) 3901-4569 /cef201sm@bol.com e Centro de Ensino Fundamental 308 de santa Maria, CL 308 A/E Santa Maria-DF, tel: 61-39016587 e 61-39016586. Tendo como instâncias institucionais professores e direção das respectivas escolas.

2.4 PÚBLICO ALVO: Alunos de Educação de Jovens e Adultos de $1^{\circ}$ e $2^{\circ}$ Segmento do Centro de Ensino Fundamental 201 de Santa Maria e alunos do 3o Segmento do Centro de Ensino Fundamental 308 de Santa Maria.

2.5 PERÍODO DE EXECUÇÃO: Deve abranger todo o semestre letivo. 


\section{AMBIENTE INSTITUCIONAL}

O Centro de Ensino Fundamental 201 de Santa Maria localiza-se na CL (Conjunto Logístico) 201. A QR 201 foi a primeira quadra a ser entregue à comunidade pelo governo Joaquim Domingos Roriz no ano de 1990. No princípio havia apenas mato, muita poeira, caminhões pipas e muita violência. Antigos inquilinos de diversas regiões do DF vieram construir aqui sua casa própria e seus sonhos de vida. Aos poucos as casas foram se multiplicando juntamente com a prole e daí a necessidade de escolas. Mas foi apenas em meados do ano de 1997 que a escola começou a ser construída como conquista da comunidade local no "Orçamento Participativo". A Escola foi inaugurada no dia 11 de fevereiro de 1998, pelo Secretário de Educação Antônio Ibañes Ruiz, o Diretor Executivo da FEDF Jacy Braga Peninha e o Senhor Governador do DF, Cristóvam Buarque, iniciando-se as aulas neste mesmo dia. Atualmente funciona nos turnos Diurno e Noturno, onde no diurno atende alunos do Ensino Fundamental II (5 $5^{\text {a }}$ a $8^{\text {a }}$ Séries e Classes de Correção de Fluxo) e, no noturno, alunos de $1^{\circ}$ e $2^{\circ}$ Segmentos de Educação de Jovens e Adultos.

De acordo com o Projeto Político Pedagógico do CEF 201 ${ }^{1}$, esta instituição tem como missão: "Oportunizar a construção de espaços que possibilitem o desenvolvimento do ser humano em seu aspecto integral, atendendo-o em suas múltiplas dimensões, a fim de fornecer-Ihe respostas éticas e eficazes para as lacunas e demandas colocadas pelo mundo contemporâneo."

As atividades mais relevantes realizadas na instituição tratam de projetos que visam sanar alguns de nossos maiores desafios, tais como: dificuldade de aprendizagem, falta de pré-requisitos, indisciplina, ausência da família na escola, diversos níveis de aprendizagem, distorção de faixa etária, desinteresse, alunos desmotivados, etc.

\footnotetext{
${ }^{1}$ O Projeto Político Pedagógico do CEF 201 é o documento que regulamenta todo o trabalho pedagógico da escola. Documento este revisado a cada início de ano letivo pela direção juntamente com todos os professores e servidores da escola.
} 
Dentre estes projetos podemos citar:

a) FECONGE - Feira de Conhecimentos Gerais - que é um grande sucesso com a participação maciça de toda comunidade escolar, com exposição de trabalhos dos mais variados temas, realizados pelos alunos e com o apoio dos professores e direção;

b) Festa Junina/Julina - que acontece todos os anos em comemoração as tradicionais festas juninas em que a cada edição faz se uma homenagem a um artista brasileiro.

A escola também realiza alguns projetos não institucionais como: as Olimpíadas Brasileiras de Matemática; Semana de Educação para a Vida; entre outros. Tem como principais atores a comunidade escolar e comunidade local. Através desses projetos a escola busca uma maior valorização do conhecimento dos alunos e resgate de alguns valores como união e estrutura familiar, aspectos culturais e regionais, e o convívio social.

Os principais desafios a serem superados giram em torno dos problemas de indisciplina e desmotivação do corpo discente gerando um baixo nível de aprendizagem.

Já o Centro de Ensino Fundamental 308 de Santa Maria está localizado á CL 308 A/E Santa Maria-DF, foi entregue a comunidade em 06 de setembro de 1994 pelo Ilmo.sr. Governador Joaquim Domingos Roriz, na época era Secretária de Educação a llma.sra . Anna Maria Dantas Antunes Villaboin e do Diretor Executivo da FEDF, o Sr. IImo. Marcos Antônio Moraes. Estruturada com doze salas de aula e as dependências administrativas.

A instituição foi fundada para atender a uma comunidade que surgiu de um assentamento, por isso é constituída de pessoas humildes que trabalham no setor de prestação de serviços e na economia informal, com famílias de baixa renda per cápita e numerosas. 
No primeiro ano de funcionamento atendia a clientela de $5^{\underline{a}}$ e $6^{\underline{a}}$ séries, no ano de 1998 ampliou-se a área construída com mais dois pavilhões passando atender de $5^{\mathrm{a}}$ à $8^{\mathrm{a}}$ séries, nos turnos matutino e vespertino. No noturno, a sede da instituição foi cedida como anexo do Centro Educacional 404 até o ano de 2006. A partir de 2004 o Centro de Ensino 308 passa a atender a clientela de $1^{\text {a }}$ á $4^{\text {a }}$ séries e no ano de 2006 atende também os alunos da EJA de Ensino Médio.

Atualmente, atendem-se os alunos do Ensino Fundamental Séries Iniciais, Ensino Fundamental Séries Finais (5 $5^{\underline{a}}$ e $6^{\underline{a}}$ série) e do EJA Ensino Médio. Um dos maiores problemas com o qual a escola se deparou é a situação de depredação do patrimônio (quebras, pichações, roubos, etc.) e de indisciplina exacerbada por boa parte da clientela atendida, por isso, no momento, todos os projetos centram no resgate da valorização da instituição e no aumento da autoestima dos professores e dos alunos. Buscando oferecer mecanismos pedagogicamente discutidos, a fim de integrar os alunos com os seus compromissos acadêmicos e também resgatando a responsabilidade das famílias com seus filhos perante a educação escolar.

A instituição busca um trabalho sociointeracionista ${ }^{2}$, pautado na pedagogia de projetos $^{3}$, assim, procura-se desenvolver o trabalho educacional permeando os valores sociais relevantes e também a interação com a realidade, transpondo a valoração do conteúdo e redefinindo a sua significação.

Nesse contexto permeia-se a evolução da capacidade de interação de toda comunidade escolar com o compromisso de promoção de um ensino público de qualidade capaz de atender as metas nacionais e principalmente promover as aprendizagens básicas imprescindíveis no processo educativo.

\footnotetext{
${ }^{2}$ Nesta abordagem o principal nome é o de L. S. Vygotsky. O Sociointeracionismo proposto por Vygotsky tinha como principal veia a interação entre os indivíduos.

${ }^{3}$ A expressão Pedagogia de Projetos pertence ao conjunto de elaborações teóricas difundidas principalmente pela francesa Josette Jolibert e por Fernando Hernández, pesquisador espanhol da Universidade de Barcelona.
} 


\section{JUSTIFICATIVA}

O projeto constitui-se da necessidade de atender de forma diferenciada aos níveis de aprendizagem em que se encontram os alunos no início do semestre, visando equalizá-los de forma sistemática, proporcionando um atendimento não somente homogêneo, mas individualizado em todo o percurso da série em que o mesmo se encontra.

Segundo Kirby e Radford (1977), diferença individual é, provavelmente, a expressão mais geral e refere-se ao estudo de todas as várias formas em que os indivíduos podem diferir uns dos outros.

$\mathrm{Na}$ sala de aula observa-se e constata-se a existência de diversos tipos de alunos, com diferenças individuais, dificuldade de aprendizagem, grandes diferenças de idades, alunos adolescentes e jovens que deixaram de ser crianças porém, ainda não são adultos, alunos diferentes por serem portadores de necessidades especiais, portanto, diferentes nos modos de pensar e agir estudando na mesma sala.

A quantidade de alunos adolescentes, cada vez crescente não é uma discussão recente, visto que a cada dia que passa aumenta um pouco mais a inserção destes alunos em classes de EJA, o que vem tornando cada vez mais difícil o tratamento das diferenças. Essa diferença faz crescer ainda mais a diversidade, que deve ser respeitada em suas características principais.

Nessa perspectiva o CNE (Conselho Nacional de Educação), juntamente com outras Secretarias discutem a proposta do aumento da faixa etária mínima para o ingresso e realização dos exames de conclusão na EJA, o que facilitaria um pouco o desenvolver das atividades em sala de aula, pois a preocupação seria menor até com a linguagem utilizada com os adultos, já que atualmente a legislação prevê uma entrada precoce aos 15 anos no primeiro segmento e 17 no Ensino Médio. (Res. № $1 \mathrm{CNE} / \mathrm{CEB}$, de 5 de julho de 2000)

Os jovens que deixaram de ser crianças e que ainda não são adultos, mas que não aproveitaram os estudos na idade e época correspondentes, juntam-se aos 
alunos adultos para estudar na mesma sala e com todas as diferenças já salientadas.

A migração do aluno adulto é, de acordo com Oliveira (1999), aquele que geralmente advém de áreas rurais, filhos de pais analfabetos ou pouco alfabetizados, pela necessidade de procurar um trabalho nem sempre qualificado, abandonando algumas vezes os estudos para poder ajudar seus pais a sustentarem os demais membros da família. Esse aluno adulto busca a escola tardiamente para alfabetizar-se, ou mesmo cursar algumas séries do ensino na Educação de Jovens e Adultos.

Ora, esses mesmos jovens têm uma maneira peculiar de falar e se expressar e, muitas vezes entram em conflito por essa diferença também na comunicação razão pela qual Kirby e Radford (1977) enfatizam a diferença individual e de personalidade de cada indivíduo.

Os jovens descritos agora como adultos saem das séries ditas normais e são transferidos para a Educação de Jovens e Adultos na condição de excluídos da escola, sendo membros de determinados grupos sociais e culturais e na condição de 'não-crianças'.

Palácios, citado por Oliveira (1999), comenta sobre o desenvolvimento após a adolescência: "A idade adulta tem sido tradicionalmente encarada como um período de estabilidade e ausência de mudanças e enfatiza a importância de considerar a vida adulta como etapa substantiva do desenvolvimento." Na verdade as mudanças e diferenças acontecem efetivamente o que muitas vezes acaba por afetar no resultado esperado por aquele professor/educador que é o de que seus alunos aprendam e apreendam com eficiência seus ensinamentos.

$\mathrm{Na}$ verdade as mudanças e diferenças acontecem efetivamente o que muitas vezes acaba por afetar no resultado esperado por aquele professor/educador que é o de que seus alunos aprendam e apreendam com eficiência seus ensinamentos.

Segundo Coll (1987) os alunos adultos muitas vezes acham-se incapazes de aprender e sentem grande vergonha de frequentar a escola depois de adultos, 
misturados às turmas onde há crianças e jovens, sentindo-se humilhados e tornando-se inseguros quanto à sua própria capacidade de aprender. Essas são diferenças individuais em sala de aula e que precisam ser atendidas pelo professor dando maior atenção aos alunos que apresentam maiores dificuldades em sua aprendizagem.

Entende-se, dessa forma, que a personalidade que traz cada indivíduo, referese a todo funcionamento individual, incluindo o seu intelecto, comportamento social e numa perspectiva mais limitada, significando principalmente o aspecto emocional e motivacional.

Ainda na visão de ensinar observando as diferenças individuais:

“... os alunos são considerados um ser histórico e social que interage com o meio físico e com o patrimônio sócio-histórico, como a linguagem, os valores, as normas, entre outros, através da convivência com diversos indivíduos, num processo pessoal de experiência mental e reflexiva sobre esses mesmos patrimônios, revendo-os e reconstituindo-os, visando incorporá-los aos conhecimentos já adquiridos." (ETTO e PEREZ ,1997, p.26-27)

Dessa forma o trabalho com as diferenças individuais se dá por compreender que mesmo uma educação que busque a homogeneidade ou o que é universal no ser humano, esbarre na diversidade, seja cultural, em conhecimento ou mesmo social.

O atual perfil da educação hoje é o senso comum. Veja por exemplo como se colocam os alunos em uma sala de aula - sentados enfileirados trabalhando individualmente, pouco se colocando ou apresentando suas ideias - o que provavelmente não é culpa apenas do professor, visto que o trabalho em grupo nem sempre é tão bem vindo assim nas classes de Educação de Jovens e Adultos.

A criação de meios que possam caracterizar uma discussão em grupo, de forma que estes possam utilizar um pouco do que Ihes são comuns, utilizando seus perfis sociais, suas diferenças e igualdades, pode não ser somente uma estratégia pedagógica de uma ou outra aula, mas uma ferramenta de acesso ao saber significativo desses alunos, para uma transferência e melhor assimilação por parte dos membros que compõem tal grupo. 
Quando a transposição desse modelo se der no âmbito geral da sala, e esta apresentar-se como uma mesa redonda, os alunos terão consigo um momento de valorização de sua capacidade intelectual e de suas vivências externas à escola, o que provavelmente é parte do aprendizado, já que:

"o conhecimento não procede nem da experiência única dos objetos nem de uma programação inata pré-formada no sujeito, mas de construções sucessivas com elaborações constantes de estruturas novas" (PIAGET, 1976 apud Freitas 2000:64).

"Quer dizer, o processo evolutivo da filogenia humana tem uma origem biológica que é ativada pela ação e interação do organismo com o meio ambiente - físico e social - que o rodeia" (COLL, 1992; LA TAILLE, 2003; FREITAS, 2000;)

O que propomos é realmente a interação entre os alunos e a facilitação de atividades que envolvam o conhecimento tanto de forma básica quanto de forma mais complexa, mas que esse conhecimento seja obtido de uma proposta de resolução de atividades que valorizem os conhecimentos prévios destes, em seus diferentes níveis.

A ideia então não é fazer com que todos saibam exatamente a mesma coisa, da mesma forma, mas que aqueles que tenham um pouco mais de conhecimento interajam com seu grupo de modo que a discussão leve a uma aprendizagem interativa entre os grupos, objetivando uma aprendizagem mais valiosa, pois essa é advinda do que cada um tem de mais importante, seja do que aprendeu em sala de aula, em seu dia de trabalho ou em sua casa.

Nesse contexto é que devemos observar as diferenças sociais, individuais, étnicas e cognitivas, que se evidenciam de forma marcante nas classes da EJA. Por isso percebemos que essas requerem um atendimento mais individualizado devido:

-A existência de grande diferença entre idade;

-A presença de alunos com vários anos de afastamento da escola;

-A heterogeneidade de níveis de conhecimentos;

-A existência de alunos trabalhadores que impede um bom acompanhamento junto aos demais alunos da turma. 
-A presença de alunos desmotivados por não conseguirem acompanhar o mesmo nível de aprendizagem dos outros.

-A inserção de muitos jovens em uma mesma turma, onde alguns deles não se identificam com a linguagem utilizada na EJA.

-A formação de turmas com grande quantidade de alunos.

A respeito deste último tópico, uma questão também deve ser observada: a estratégia inicial de matrícula e a utilização da SOME (solicitação de matrícula escolar) onde é preciso evitar um número muito grande de alunos dentro de uma mesma classe de EJA, para que o desenvolvimento de atividades individuais e, em grupo possa atender melhor a necessidade destes alunos.

A proposta deste projeto é a tentativa de criação de turmas compostas por no máximo 30 alunos e matriculados de forma a atender uma menor variação na faixa etária possível, no inicio de cada semestre letivo, contudo essa proposta ainda está em estudo pela direção e secretaria escolar.

Nessa perspectiva, proporcionar aos alunos um atendimento que os envolva de forma mais efetiva durante as aulas é de fundamental necessidade, buscando uma melhoria considerável tanto na aprendizagem quanto na inserção do mesmo na sociedade como um todo. 


\section{OBJETIVO GERAL:}

Promover a inserção dos alunos em sala de aula respeitando os diversos níveis de aprendizagens individuais e coletivos por meio de atividades que visam atendêlos em suas necessidades reais.

\subsection{OBJETIVOS ESPECÍFICOS:}

-Atender aos alunos de forma individualizada de acordo com os níveis de aprendizagem diagnosticados no início do semestre letivo.

-Promover a troca de experiências entre os diversos grupos constituídos.

-Desenvolver o respeito mútuo entre os alunos através da adequação de atividades.

-Equalizar o nível de aprendizagem de forma mais dinâmica diminuindo cada vez mais as diferenças encontradas entre os alunos.

-Elevar o nível de conhecimento da turma como um todo. 


\section{ATIVIDADES}

O projeto se desenvolverá conforme os seguintes passos:

\section{1ํ Passo - Introdução e abertura do projeto:}

Para introdução do projeto, cada sala deverá ter uma aula inaugural com a seguinte tarefa:

- Criação de cartazes com um breve histórico dos alunos de cada turma em cada um dos três segmentos de EJA, visando à reflexão do aluno como um ser que possui suas diferenças que devem ser respeitadas e vista como forma de experiência por cada um em sua convivência em sala, na escola e na vida, através da provocação nos seguintes tópicos:

- Quem eu sou?

- De onde vim?

- Como estou?

- O que pretendo ser?

- Que objetivos pretendo atingir?

Observação: Essa reflexão deverá ser retomada ao final do semestre como uma auto-avaliação, no intuito de verificar as mudanças atingidas por cada um.

Essa tarefa deve ser orientada por cada professor regente. A aula inaugural pode ser feita durante a primeira semana do semestre letivo.

- Durante essa primeira semana, serão tiradas fotos dos alunos para criação de uma apresentação de slides a ser exibida durante a abertura do projeto.

- Após a aula inaugural deverá ser feita uma abertura oficial do projeto, no pátio da escola, com as seguintes atividades:

- Apresentação da direção e do corpo docente da escola. 
- Exposição do que é o projeto Diferenças Individuais na Sala de EJA, no pátio da escola com a participação de todos os professores, direção e alunos.

- Exibição da apresentação de slides com as fotos tiradas durante a semana da aula inaugural, fazendo com que os alunos sintam-se parte principal e fundamental do projeto.

- Leitura dos históricos de cada turma, por um dos alunos escolhidos em sala.

- Convite aos alunos mais jovem e o mais idoso para que estes contem um pouco da história de sua vida.

Esse histórico dará a toda a escola a possibilidade de conhecer a história de vida, as origens, dificuldades e pretensões destes alunos.

- Finalização da abertura do projeto com a exibição do vídeo: Aceite as diferenças.

\section{Passo - Desenvolvimento de atividades pedagógicas em sala de aula.}

No decorrer do semestre algumas atividades serão feitas em sala, como por exemplo:

- Diagnóstico do nível de aprendizagem de cada aluno no início do semestre. Esse diagnóstico pode ser realizado, tanto através de observações diretas do professor, quanto perante aplicação de atividades envolvendo conteúdos básicos da série em que o aluno se encontra.

- Distribuição dos alunos em grupos de acordo com o nível de aprendizagem diagnosticado.

- Organização de listas de atividades que atendam a cada um dos diversos grupos.

- Distribuição de atividades para os grupos em questão. 
- Esclarecimento com relação às dúvidas dos grupos priorizando os que demonstram maiores dificuldades de aprendizagem.

- Incentivo ao aluno a busca pelo próprio conhecimento através de pesquisas em livros didáticos, sites de internet, bibliotecas e outros.

- Criação e orientação do "Dia da diferença: Show de Talentos" em data a ser marcada no meio do semestre incentivando os alunos a criarem apresentações teatrais, músicas, desenhos, pinturas, danças, contar causos e piadas visando à valorização e respeito às habilidades individuais de cada um. É importante frisar que tais apresentações serão desenvolvidas pelos alunos no decorrer dos dois primeiros meses, e que essas apresentações serão organizadas por eles juntamente com seus professores.

\section{3o Passo - Desenvolvimento do Dia da Diferença - Show de Talentos.}

Objetivando a continuidade e incentivo ao projeto, será proporcionado aos alunos o "Dia da Diferença - Show de talentos", com as atividades a serem desenvolvidas no pátio da escola:

- Palestra com a Orientação Educacional - SOE sobre diferenças individuais.

- Apresentação do Show de Talentos, criados pelos alunos e orientados pelos professores.

Sugestão: As apresentações feitas no Dia da Diferença poderão ser utilizadas como item de avaliação por parte dos professores de primeiro segmento bem como de cada disciplina de segundo e terceiro segmentos.

Em sala deverá ser retomada as atividades pedagógicas propostas anteriormente nos próximos meses até o fim do semestre. Nesse período é importante que o professor esteja atento ao surgimento de novas duvidas ou necessidades por parte dos alunos para que sejam criadas novas intervenções que potencializem sua aprendizagem. 


\section{4ํPasso - Culminância do projeto.}

Como fechamento do projeto, serão feitas as seguintes atividades:

- Criação de cartazes com desenhos, pinturas, colagem de imagens que demonstrem a mudança ocorrida em sua vida pela convivência deste na escola durante o semestre. É sugestão nesse momento, que os cartazes não contenham frases, mas apenas imagens, com o objetivo de utilização de uma nova forma de leitura da vida.

- Exposição dos cartazes, em sala para visitação por parte de toda a comunidade escolar e local, se possível, com explicação destes por cada aluno que o confeccionou.

- Convite aberto à direção e aos professores para que estes façam explanação do que foi o projeto e incentivo ao mesmo nos semestres seguintes. 
7. CRONOGRAMA

A aplicação do projeto deverá ocorrer sempre no início do semestre e se estender ao longo do mesmo. 


\section{PARCEIROS}

O projeto Diferenças Individuais em Sala de Aula de EJA, não conta com parceria externa à escola, visto que o mesmo será trabalhado com algumas atividades variadas fora de sala de aula, porém em sua maioria, serão atividades pedagógicas dentro desta.

Como parceiros, sabemos que é de extrema importância a participação de toda a comunidade escolar desse modo, destacamos a parceria:

- da Direção da Escola;

- do Serviço de Orientação Educacional - SOE;

- dos professores de 1ํ, $2^{\circ}$ e $3^{\circ}$ segmentos das escolas CEF 201 Santa Maria e CEF 308 Santa Maria.

- da secretaria da escola, através da estratégia de matrícula com o formulário da SOME e adaptação deste quando necessário.

- demais membros da comunidade escolar, como os servidores, através da organização de materiais, do local a ser desenvolvido a apresentação inicial e final, e dos familiares dos alunos como convidados a prestigiarem as apresentações e apoio a estes, durante o desenvolvimento do projeto.

E principalmente:

- dos alunos dos três segmentos de Educação de Jovens e Adultos das referidas escolas em Santa Maria. 


\section{ACOMPANHAMENTO E AVALIAÇÃO}

O projeto Diferenças Individuais na Sala de Aula de EJA, é uma proposta ainda não implementada, porém já apresentada à direção da escola de forma a ser discutida com o corpo docente visando a sua implementação no segundo semestre letivo do ano de 2010.

Dessa forma tanto o projeto em si, quanto o acompanhamento e a avaliação aqui descritos, poderão sofrer algumas alterações, visto que caberá sugestões desses sujeitos para melhor desenvolvimento das atividades aqui propostas.

Quanto à avaliação:

- Observação do desempenho do aluno, de forma continuada, avaliando se está ou não acompanhado as atividades propostas, caso contrário rever as atividades e as dificuldades relatadas pelo aluno.

- Realocação dos alunos em outros grupos de acordo com o desempenho alcançado através de novas atividades diagnósticas.

- Monitoria de forma continua do desempenho do aluno.

- Realização das devidas intervenções em momentos oportunos, usando como ponto de partida a curiosidade do aluno. 


\section{REFERÊNCIAS BIBLIOGRÁFICAS}

BRASIL. Ministério da Educação. RESOLUÇÃO CNE/CEB № 1, DE 5 DE JULHO DE 2000, Estabelece as Diretrizes Curriculares Nacionais para a Educação e Jovens e Adultos. Disponível em:

$<$ http://www.diaadia.pr.gov.br/ceja/arquivos/File/resol_01_2000_CNE.pdf>. Acesso em 26/06/2010.

BRASIL. Ministério da Educação. UNB/FE. Curso de Especialização em Educação na Diversidade e Cidadania, com Ênfase em EJA. Módulo VI. Disponível em: $<$ http://www.fe.unb.br/eja/mod/forum/discuss.php?d=608 >. Acesso em 26/06/2010.

COLL, C. As contribuições da Psicologia para a Educação: Teoria Genética e Aprendizagem Escolar. In LEITE, L.B. (Org) Piaget e a Escola de Genebra. São Paulo: Editora Cortez,1992. p. 164-197.

COLL,C.; GILLIÈRON. C. Jean Piaget: O desenvolvimento da inteligência e a construção do pensamento racional. In, LEITE, L.B. (Org) Piaget e a Escola de Genebra. São Paulo: Cortez, 1987. p. 15-49

ETTO, Maria Cristina e PEREZ, Maria Regina, Trabalho Diversificado: procedimento que atende às diferenças individuais dos alunos. Disponível em:<http:// www.construirnoticias.com.br/asp/materia.asp?id=1425 >. Acesso em $10 / 12 / 2009$

FREITAS, M.T.A. de. Vygotsky e Bakhtin: Psicologia e Educação: um intertexto. São Paulo: Editora Ática, 2000

KIRBY, Richard e RADFORD, John. Diferenças Individuais. Rio de Janeiro: Zahar, 1977.

LA TAILLE., Y. Prefácio. In, PIAGET, J. A construção do real na criança. 3.ed. São Paulo: Editora Ática, 2003.

OLIVEIRA, Marta Kohl de. Jovens e Adultos Como Sujeitos de Conhecimento e Aprendizagem. 1999 15p. (Trabalho apresentado na XXII Reunião Anual da ANPEd), Faculdade de Educação, Universidade de São Paulo, Caxambu, 1999. . Disponível em: <http: //www. cinterfor. org. uy/public/ spanish/region /ampro/cinterfor /temas/youth/doc/not/libro286/libro286.pdf.>. Acesso em 05/04/201 
ANA MARIA DE ALBUQUERQUE SANTOS - amasann@ig.com.br

GENIVAL SANTOS DE MORAES - geninhomensagens@yahoo.com.br

GILDO BEZERRA DOS SANTOS - gildobezerra@yahoo.com.br

\title{
DIFERENÇAS INDIVIDUAIS NA SALA DE AULA DE EJA
}

\author{
ENDEREÇOS DA INTERVENÇÃO \\ CEF 201 de Santa Maria - CL 201 de Santa Maria-DF \\ CEF 308 de santa Maria - CL 308 A/E Santa Maria-DF
}

\section{AMBIENTE INSTITUCIONAL}

O CEF 201 de Santa Maria funciona nos turnos Diurno, com alunos do Ensino Fundamental II e Noturno, alunos de $1^{\circ}$ e $2^{\circ}$ Segmentos da EJA.

O CEF 308 de Santa Maria atende, alunos do Ensino Fundamental - Séries Iniciais, e Séries Finais ( $5^{\mathrm{a}}$ e $6^{\mathrm{a}}$ série) e ao EJA $3^{\circ}$ Segmento.

\section{JUSTIFICATIVA E CARACTERIZAÇÃO DO PROBLEMA}

- O projeto se justifica pela necessidade de atender de forma diferenciada aos diversos níveis de aprendizagem em que se encontram os alunos.

- Grande diferença entre idade e alunos com vários anos de afastamento da escola.

- Níveis de conhecimentos bastantes heterogêneos devido à inserção de muitos jovens em uma mesma turma, onde alguns deles não se identificam com a linguagem utilizada na EJA.

- Alunos desmotivados por dificuldade no acompanhamento em relação a outros.

\section{OBJETIVOS}

- Respeitar os diversos níveis de aprendizagens individuais e coletivos.

- Elevar o nível de conhecimento dos alunos.

- Equalizar o nível de aprendizagem de forma mais dinâmica.

\section{ATIVIDADES}

- Criação de cartazes com um breve histórico dos alunos de cada turma;

- Criação e exibição de slides com fotos dos alunos;

- Exibição do vídeo: Aceite as diferenças.

- Distribuição dos alunos em grupos, criação de listas de atividades e distribuição destas nos grupos, com orientação do professor;

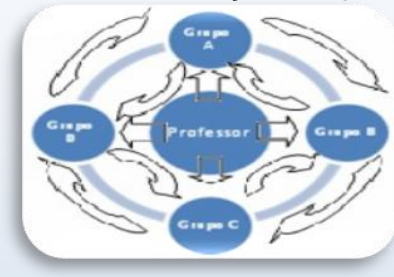

- Palestra com a Orientação Educacional sobre diferenças individuais e apresentação do Show de Talentos.

- Criação de cartazes com desenhos, pinturas, colagem de imagens e exposição dos mesmos.

\section{PERÍODO DE REALIZAÇÃO}

A aplicação do projeto deverá ocorrer sempre no início do semestre e se estender ao longo do mesmo.

\section{PARCEIROS}

Direção, professores, membros da comunidade escolar e alunos.

\section{REFERÊNCIAS}

- COLL, C. As contribuições da Psicologia para a Educação: Teoria Genética e Aprendizagem Escolar. In LEITE, L.B. (Org) Piaget e a Escola de Genebra. São Paulo: Editora Cortez,1992. p. 164-197.

- COLL,C.; GILLIĖRON. C. Jean Piaget: O desenvolvimento da inteligência e a construção do pensamento racional. In, LEITE, L.B. (Org) Piaget e a Escola de Genebra. São Paulo: Cortez, 1987. p. 15-49

- ETTO,Maria Cristina e PEREZ,Maria Regina, Trabalho Diversificado: procedimento que atende às diferenças individuais dos alunos. Disponível em:<http:// www.construirnoticias.com.br/asp/materia.asp?id=1425 >. Acesso em 10/12/2009

- FREITAS, M.T.A. de. Vygotsky e Bakhtin: Psicologia e Educação: um intertexto. São Paulo: Editora Ática, 2000

- KIRBY, Richard e RADFORD, John. Diferenças Individuais. Rio de Janeiro: Zahar,1977.

- LA TAILLE., Y. Prefácio. In, PIAGET, J. A construção do real na criança. 3.ed. São Paulo: Editora Ática, 2003.

- OLIVEIRA, Marta Kohl de. Jovens e Adultos Como Sujeitos de Conhecimento e Aprendizagem. 1999 15p. (Trabalho apresentado na XXI Reunião Anual da ANPEd), Faculdade de Educação, Universidade de São Paulo, Caxambu, 1999. . Disponível em: http://www.cinterfor.org.uy/public/spanish/region/ampro/cinterfor/temas/youth/doc/not/libro286/libro286.pdf. Acesso em 05/04/201 